\title{
COMPUTER COMPETENCY AS AN INDICATOR OF HEALTHCARE INSTITUTION READINESS FOR HEALTH INFORMATION SYSTEMS: A STUDY IN BENGHAZI
}

\author{
Salah Awami \\ University of Benghazi, Benghazi - Libya
}

\begin{abstract}
Background: Healthcare professionals' computer competency is one aspect of healthcare institutions' readiness assessment for the implementation and adoption of health information systems (HIS). Computer competent healthcare professionals normally have a positive attitude toward HIS which is considered to be an important facilitating factor for the implementation process.

Aim: To discuss computer competency in healthcare and investigate computer competency of healthcare professionals in four healthcare institutions in Benghazi.

Methods: The cross-section qualitative research administered a questionnaire to collect data from four healthcare institutions in Benghazi; aspects evaluated were related to computer use, understanding of IT concepts, and general attitudes toward computers. With a 69\% response rate; 93 participants (physicians, nursing staff and public health practitioners) filled the questionnaire.

Results: The majority of the participants think that computers could be useful for their work and that they have confidence in using them. $29 \%$ of the participants use computers at work and the same percentage have attended formal training in IT. Data entry could be a challenge for using computers, particularly among physicians. There is also a knowledge gap about important underlying IT concepts among healthcare professionals in these institutions.

Conclusion: Healthcare professionals at these institutions are likely to have a positive attitude toward any future HIS implementations. Lack of use of computers at work, lack of formal IT training, and data entry challenges are some of the issues that need to be addressed before any realistic implementation can be considered.
\end{abstract}

\section{KEYWORDS}

Computer Competency, Computer Literacy, Readiness Assessment, HIS Implementation, HIS in Benghazi

\section{INTRODUCTION}

Healthcare professionals' positive perception of health information systems (HIS) (Dansky, Gamm et al. 1999) and their level of confidence in dealing with computers in general (Terry, Giles et al. 2009) are critical factors for the successful adoption and implementation of these systems. Thus, computer literacy of healthcare professionals is an important aspect to be considered (Van der Meijden, Tange et al. 2001; Štepankova and Engova 2006; Simon, Kaushal et al. 2007; Li, Talaei-Khoei et al. 2013; Mills, Francis et al. 2015; Correia, Lapão et al. 2017) particularly when assessing organizations' readiness for embracing information and communication technology (ICT)(Saleh, Khodor et al. 2016). Computer competent healthcare professionals with proper experience and use of computers typically have the needed computing skills, appreciate the potentials of HIS and have the necessary positive attitude (Mannan, Murphy et al. 2006; Simon, Kaushal et al. 2007; Ward, Pollard et al. 2007; Ludwick and Doucette 2009).

\subsection{Computer Competency}

Computer literacy is defined as the skills and competencies needed to use computer hardware and software effectively, it reflects familiarity and positive attitude toward computers (Ferrari 2012). Additionally, it enables 
basic computer skills such as comfortable use of the keyboard for data entry which can be a determinant factor in using HIS (Ludwick and Doucette 2009; Terry, Giles et al. 2009). Computer competency, another term used in this context, refers to using computers to accomplish job tasks, which reflects a deeper knowledge and more intellectual abilities than the mere learning of computer hardware and software (Lin 2011). Computer competency involves understanding three kinds of knowledge: contemporary skills (the ability to use available information technology applications), foundational concepts (the basic principles of IT) and intellectual capabilities (the ability to use IT for organizing, reasoning, and problem solving)(Hoffman and Blake 2003).

Formal education has been offered to qualify healthcare professionals to be computer competent (Rigby, Hulm et al. 2007), including incorporating health informatics courses within the curriculum of health science educational programs. Besides obtaining the IT knowledge and skills, such courses make students appreciate the importance, potentials, and risk of 'health ICT' and positively influence students' trust in and adoption of ICT in healthcare at their workplace in the future (Gibson and Silverberg 2000; Lam, Amon et al. 2012). ICT understanding and use can also be achieved informally which might be effective particularly when technology is related to trainees' lives. However, informal knowledge covers the simple use of the technology that is considered meaningful to the individual at that time with little information about underlying concepts (Hoffman and Blake 2003).

Information literacy is another term used in this context referring to competencies and skills required to find, evaluate, understand, and use information (Association 2000). Information literacy is supported and enabled by computer literacy and is concerned with addressing modern-day information issues such as abundance, diversity of sources, diversity of formats, and authenticity.

The term literacy is often used with other terms to refer to similar concepts such as digital literacy, ICT literacy, e-literacy, network literacy, and media literacy (Bawden 2008). Worth mentioning as well, is cyber literacy, a term emerged recently to emphasize important features of the internet that need to be considered such as speed, reach, anonymity, and interactivity as well as the social topics of gender, online rage, hoaxes, and privacy (Hoffman and Blake 2003).

\subsection{Readiness Assessment}

The readiness assessment is considered an essential HIS pre-implementation requirement because it highlights the importance of effective planning to evaluate the institution's preparedness for change and embracing technical innovations and awareness of and responsiveness to factors affecting HIS implementation (Terry, Giles et al. 2009). Many readiness assessment frameworks have been presented in the literature which, generally, focus on aspects related to organization infrastructure, management support, government policies, and end-users' skill level and attitudes. Factors related to end-users include time to learn, awareness of IT usefulness, trusting IT, staff exposure to computers, computer anxiety and IT education. Therefore, assessing healthcare professionals' IT skills and addressing shortages through training courses become essential (Adjorlolo and Ellingsen 2013). Assessing the IT literacy of end-users may also identify the 'engagement' construct of a readiness assessment framework which addresses issues of awareness of IT usefulness and trust (Li, Land et al. 2008).

This study explores healthcare professionals' computer competency in selected healthcare institutions in Benghazi and provides a snapshot of the extent of healthcare providers' use of computers in these institutions. Furthermore, this outcome reflects on an important aspect of these organizations' readiness for IT adoption.

\section{METHODS}

This cross-section qualitative research used a semi-structured self-administered questionnaire for data collection from a non-probabilistic sample from three hospitals and a medical center in Benghazi city. The participants were recruited from Al-Kwaifia Chest Hospital, Al-Hwari General Hospital, the Nephrology Center of Benghazi, and Benghazi Medical Center over the period of July 2019 to October 2019. All of these healthcare institutions are run and financed by the Libyan government. The questionnaire has close-ended, open-ended and partially structured questions to gauge understanding of healthcare professionals' ICT knowledge and skill levels and awareness and attitudes toward IT and HIS.

The study sample was diverse including participants of different genders, various healthcare specialties, and different age groups and work experiences. As a qualitative research the emphasis was on the relevance of 
the sample subjects rather than representativeness (Neuman 2014). Therefore, selected sample sufficiently provides us the information and understanding we seek about a social world.

The 25 item questionnaires were distributed to healthcare professionals in the designated institutions mainly via the head or staff of medical affairs departments who invited their employees to participate. The researcher collected the filled out questionnaires from the department office later on completion. Occasionally, the researcher approached the subjects directly whenever that was possible. There were two versions of the questionnaire: an English version distributed to physicians and public health specialists and an Arabic version targeted nursing staff.

Five aspects were examined to reflect on the subjects' computer competency: the use of computers, awareness of IT potentials and challenges, knowledge of computer components, aspects of information literacy, and general attitudes towards information technology application in healthcare.

The use of computers aspect was contemplated through posing direct questions of whether subjects are using computers at work, at home or even searching for work-related information on their mobile phones, in addition to posing questions about application software use and frequency of use.

Awareness of computer potentials and challenges was assessed by posing a question on choosing important features of computers that subjects appreciate most. Other questions explored their knowledge, awareness, and comments about data entry challenges, computer security threats and counteraction measures, communication support, and electronic medical records.

Knowledge of computer components (i.e. processor, RAM, HD, and screen size.) was probed through posing a question about a hypothetical situation where subjects decide what computer components they would consider if they were to buy a computer. The question also elicits subjects' knowledge of the units of measurement for every component and added the computer price as a property that might be considered. Another question in this context reflected on their awareness of their computer's connection to a LAN.

The information literacy aspect was contemplated through posing questions about whether they are using the web to search for work-related information, frequency of use, what information sources they are using, and whether they considered information validation. Similarly, their awareness and handling of web site cookies.

The general attitude of subjects about the application of IT and the use of computers was probed through direct questions on their opinion about the importance of using computers at work, ease of computer use, and trusting computers with work-related data. Participants' level of enthusiasm was also explored by eliciting their suggestions and concerns about using computers at their work.

Users also were asked whether they have attended a course to learn about computers. Another question pertained to their role with any system development process to evaluate their knowledge of the concept of user participation with the system development team.

\section{RESULTS}

134 questionnaires were distributed and 93 were collected, 2 of the returned questionnaires were discarded due to insufficiency. Table 1 summarizes the demographic data of the participants and Table 2 summarizes the study results.

Table 1. Demographic data of the participants

\begin{tabular}{lccc}
\hline Variable & Category & Number & Percentage \\
\hline Occupation & Physicians & 31 & $33 \%$ \\
& Public health practitioners & 12 & $13 \%$ \\
Years of experience & Nursing staff & 50 & $54 \%$ \\
& $<1$ & 6 & $6.5 \%$ \\
& $1-5$ & 27 & $30 \%$ \\
& $6-10$ & 28 & $31 \%$ \\
& $11-15$ & 16 & $17.5 \%$ \\
Gender & $16-20$ & 5 & $5.5 \%$ \\
Age group & $>20$ & 9 & $10 \%$ \\
& Male & 26 & $28.5 \%$ \\
& Female & 65 & $71.5 \%$ \\
& $20-30$ & 23 & $25 \%$ \\
& $31-40$ & 57 & $63 \%$ \\
& $41-50$ & 9 & $10 \%$ \\
& $51-60$ & 2 & $2 \%$ \\
\hline
\end{tabular}


Table 2. Results of the study

\begin{tabular}{|c|c|c|c|}
\hline Participants who & Number & $\begin{array}{l}\text { Percentage } \\
(\mathrm{n}=91)\end{array}$ & Comments \\
\hline Use computers at work. & 27 & $29 \%$ & \\
\hline $\begin{array}{l}\text { Use computers at home but not at } \\
\text { work for work-related tasks. }\end{array}$ & 36 & $39 \%$ & \\
\hline $\begin{array}{l}\text { Use mobile phone for work-related } \\
\text { tasks AND no use of computers at } \\
\text { all. }\end{array}$ & 20 & $21 \%$ & \\
\hline $\begin{array}{l}\text { Do not use computers nor mobile } \\
\text { phone for work-related tasks at all. }\end{array}$ & 7 & $8 \%$ & All from nursing staff. \\
\hline Use MS Word for work. & 59 & $64 \%$ & $20 \%$ of them $(n=12)$ stated daily use. \\
\hline Use MS Excel for work. & 30 & $32 \%$ & $10 \%$ of them $(n=3)$ use the software daily. \\
\hline Use MS Access for work. & 21 & $23 \%$ & Only 3 participants stated daily use. \\
\hline $\begin{array}{l}\text { Think that computers are either } \\
\text { very important or important. }\end{array}$ & 67 & $73 \%$ & \\
\hline $\begin{array}{l}\text { Think that computers are not } \\
\text { important for work. }\end{array}$ & 11 & $12 \%$ & \\
\hline $\begin{array}{l}\text { Think that computers are either } \\
\text { very easy or easy to use. }\end{array}$ & 62 & $68 \%$ & \\
\hline $\begin{array}{l}\text { Think that data entry and keyboard } \\
\text { use can be a challenge. }\end{array}$ & 26 & $28 \%$ & 18 physicians think that compared with 8 nurses. \\
\hline Trust computer with work data. & 59 & $64 \%$ & \\
\hline $\begin{array}{l}\text { Take necessary measures to protect } \\
\text { data. }\end{array}$ & 74 & $81 \%$ & $\begin{array}{l}\text { Of them, more are in favour of password protection } \\
(59 \%, n=44) \text { than making backups }(30 \%, n=22) \text {. } \\
\text { Only very few }(11 \%, n=8) \text { take both measures. }\end{array}$ \\
\hline $\begin{array}{l}\text { Think that having antivirus } \\
\text { software running in computer is } \\
\text { very important. }\end{array}$ & 59 & $65 \%$ & $\begin{array}{l}\text { Most of the remaining participants }(35 \%, n=32) \\
\text { didn't know or were undecided. }\end{array}$ \\
\hline $\begin{array}{l}\text { Are aware of their computers' } \\
\text { connection to a local network. }\end{array}$ & 83 & $91 \%$ & Stating 'yes' or 'no' they are connected. \\
\hline $\begin{array}{l}\text { Demonstrated adequate knowledge } \\
\text { about computer components. }\end{array}$ & 7 & $8 \%$ & $\begin{array}{l}\text { Specified several components that matters to their } \\
\text { decision to purchase a computer and their measuring } \\
\text { units. }\end{array}$ \\
\hline $\begin{array}{l}\text { Indicated lack of knowledge about } \\
\text { computer components. }\end{array}$ & 84 & $92 \%$ & $\begin{array}{l}56 \% \text { of all participants }(n=51) \text { chose some } \\
\text { components without specifying units of } \\
\text { measurement. } 36 \% \text { of all participants }(n=33) \text { chose } \\
\text { 'the price', didn't know, or were undecided. }\end{array}$ \\
\hline $\begin{array}{l}\text { Attended a training course about } \\
\text { computers. }\end{array}$ & 27 & $29 \%$ & \\
\hline $\begin{array}{l}\text { Taught themselves about } \\
\text { computers. }\end{array}$ & 52 & $57 \%$ & \\
\hline $\begin{array}{l}\text { Use electronic communication for } \\
\text { work. }\end{array}$ & 65 & $71 \%$ & \\
\hline $\begin{array}{l}\text { Use the web to search for work- } \\
\text { related information. }\end{array}$ & 58 & $63 \%$ & $\begin{array}{l}\text { Mostly physicians and only } 27 \% \text { of them }(n=16) \\
\text { search on a daily basis. }\end{array}$ \\
\hline $\begin{array}{l}\text { Specified web sites they visited to } \\
\text { search for work-related } \\
\text { information. }\end{array}$ & 49 & $53 \%$ & $75 \%$ of them $(n=37)$ are physicians. \\
\hline Handle web sites cookies. & 67 & $73 \%$ & \\
\hline
\end{tabular}




\begin{tabular}{|c|c|c|c|}
\hline Reject web sites cookies. & 23 & $25 \%$ & $\begin{array}{l}\text { Very few of them provided reasons for rejection } \\
\text { which included: harm to computer and lack of trust. }\end{array}$ \\
\hline $\begin{array}{l}\text { Validate information from web } \\
\text { sites. }\end{array}$ & 25 & $27 \%$ & $\begin{array}{l}26 \% \text { of all participants }(n=24) \text { do not validate and } \\
46 \%(n=42) \text { didn't answer the question. }\end{array}$ \\
\hline Know about EMR. & 58 & $63 \%$ & $\begin{array}{l}24 \% \text { of them }(n=14) \text { stated knowing a lot about } \\
\text { EMR. }\end{array}$ \\
\hline $\begin{array}{l}\text { Think that EMR will be beneficial } \\
\text { to their work. }\end{array}$ & 63 & $69 \%$ & \\
\hline $\begin{array}{l}\text { Think that they can be part of HIS } \\
\text { development or acquisition } \\
\text { processes. }\end{array}$ & 25 & $27 \%$ & \\
\hline $\begin{array}{l}\text { Didn't know whether there is a } \\
\text { role for them in the development } \\
\text { or acquisition processes of EMR. }\end{array}$ & 42 & $46 \%$ & \\
\hline
\end{tabular}

With regards to the computer features that participants appreciate most, a third of them chose at least three features, $40 \%$ chose only one feature and $7 \%$ chose none. The most appreciated computer features were data storage and information search and retrieval; and then the ability to share and transfer data and electronic communication. Visual presentation of data, data analysis, and decision support were the least appreciated features of the computer for the participants.

$30 \%$ of participants provided extra comments and suggestions at the final question of the questionnaire. Nurses' group comments were mainly about the lack of availability of computers at work and suggestions for provision of training courses to increase their computer knowledge and skills. Some also noted that using information systems allow better patient data management.

Physicians' notes and comments varied and included supporting the activation of HIS, requests for organizing training programs, and enumerating benefits and drawbacks of using computers at work. Benefits mentioned included better patient data management and making work easier. Drawbacks mentioned included virus attacks and network failure. One physician was skeptical and commented that minimal outcomes can be achieved from using computers at work.

\section{DISCUSSION}

The data analysis provides insights into the healthcare professionals' computer competency and the extent of computer use in the targeted healthcare institutions which were the main objectives of this study.

The low percentage of healthcare professionals using computers at work in addition to the low frequency of use indicate that computers are not in actual and meaningful use to support work-related tasks, despite the existence of a considerable number of healthcare professionals who use computers at home to perform work-related tasks. MS Word is the application software most used by participants, which suggests that computers are mainly used for simple tasks such as document and report creation and editing. A lesser percentage of the participants use more sophisticated software such as Excel and Access. The majority appreciate the computers' ability to store data, search for information, and support communication. There seems to be a lack of understanding and appreciation of the computers' ability to analyze data and support decisions.

The majority of participants perceives computers as useful tools for their work and state that they are easy to use. Although some of the physicians thought that using a keyboard poses a challenge to using computers. This suggests that routine data entry accompanying the use of HIS might prove to be a challenge.

An important percentage of participants trust computers with data and are aware of some of the security measures that can be taken to protect them. The majority of data security-vigilant healthcare providers chose using passwords as protection. At the same time, a low percentage of participants were inclined to make data backups.

Participants' knowledge of computers' hardware is insufficient, with only a few demonstrating an adequate understanding of computer hardware components by choosing one or more components they would consider when purchasing a computer and specifying units of measure. 
Some of the participants attended training courses to learn about operating systems and some productivity software. However, the majority gained their computer skills informally which could undermine their knowledge of important underlying concepts of computers and IT. This outcome was supported by having a low percentage of participants using application software providing decision support and problem-solving capabilities such as Excel and Access. In addition a high percentage of participants did not know whether there is a role for them to play in HIS development/acquisition process.

A significant percentage of participants communicate with their colleagues electronically about work-related issues. However, they use email services and social media platforms provided on the web. Consequently, these healthcare institutions are missing the opportunity of capturing these conversations as well as risking the confidentiality and integrity of work-related data.

A considerable number of participants use and interact with the web to look up work-related information, although the low frequency of use and lack of information validation suggests the requirement for more training in information literacy.

A considerable percentage of participants stated having some knowledge about electronic medical records. However, a few stated knowing a lot about EMR and it is not clear how they gained this knowledge given that none of the participating healthcare institutions are using any form of electronic medical records systems. Nonetheless, this knowledge seems to have positively affected their opinion about the importance of EMR.

The study provides insightful findings regarding the computer competency of healthcare providers at the designated healthcare institutions. The number of participants could have been greater, particularly at large institutions such as Benghazi Medical Centre, but many healthcare professionals were reluctant to participate. Perhaps there would have been more participants had the researcher approached the subjects directly. Moreover, data quality of self-administered questionnaires can suffer due to participants' misunderstanding of some of the questions, lack of concentration, bias or language barriers. Also, triangulation of research methods could have revealed more details and confirmed some findings.

\section{CONCLUSION}

Proper planning for HIS implementation requires conducting readiness assessment for the targeted institutions. Many readiness assessment frameworks have been suggested which consider healthcare professionals' attitudes, knowledge and skills in computers as an important aspect. Computer competency is concerned with understanding and gaining knowledge and skills in computers and IT. This study investigated the computer competency of healthcare professionals in some healthcare institutions in Benghazi to assess one aspect of these institutions' readiness for any prospective HIS implementation.

Healthcare providers in the selected healthcare institutions have a positive attitude toward computers. Their level of confidence in dealing with computers is relatively high and was inferred from the high percentage of participants who think computers are important and easy to use, as well as trusting computers with their work data. Characteristics of such a workforce enable the recruitment of enthusiastic change agents - another determinant of successful HIS implementation.

However, the low percentage of users using computers at work and dearth of knowledge about some aspects and concepts of information technology are some of the drawbacks that need to be addressed. Setting up local area networks and providing basic web services such email communication is one solution for integrating computers into the daily work practice of healthcare professionals in these institutions. Furthermore, knowledge and skill gaps of healthcare professionals can be addressed by providing adequate education and training in ICT and health informatics.

As far as readiness assessment of these healthcare institutions is concerned this study examined only one aspect related to healthcare professionals' computer competency. Other aspects of readiness assessment that need to be considered in the future to have a comprehensive assessment, include management support, government policies, and IT infrastructure. 


\section{REFERENCES}

Adjorlolo, S. and G. Ellingsen (2013). "Readiness assessment for implementation of electronic patient record in Ghana: a case of university of Ghana hospital." Journal of Health Informatics in Developing Countries 7(2).

Association, A. L. (2000). "Information literacy competency standards for higher education."

Bawden, D. (2008). "Origins and concepts of digital literacy." Digital literacies: Concepts, policies and practices 30: 17-32.

Correia, J. C., L. V. Lapão, et al. (2017). "Implementation of a Telemedicine Network in Angola: Challenges and Opportunities." Journal of Health Informatics in Developing Countries 12(1).

Dansky, K. H., L. D. Gamm, et al. (1999). "Electronic medical records: are physicians ready?" Journal of Healthcare Management 44(6): 440-454.

Ferrari, A. (2012). Digital competence in practice: An analysis of frameworks, Luxembourg: Publication office of the EU. Research Report by the Joint ....

Gibson, K. E. and M. Silverberg (2000). "A two-year experience teaching computer literacy to first-year medical students using skill-based cohorts." Bulletin of the Medical Library Association 88(2): 157-164.

Hoffman, M. and J. Blake (2003). "Computer literacy: Today and tomorrow." Journal of Computing Sciences in Colleges 18(5): 221-233.

Lam, M. K., K. L. Amon, et al. (2012). The effect of e-health contents on health science students' attitude toward the efficiency of health ICT in care provision. HIC.

Li, J., L. P. W. Land, et al. (2008). "E-Health readiness framework from Electronic Health Records perspective." GlobDev 2008: 4.

Li, J., A. Talaei-Khoei, et al. (2013). "Health care provider adoption of eHealth: systematic literature review." Interactive journal of medical research 2(1): e7.

Lin, T.-C. (2011). "A Computer Literacy Scale for Newly Enrolled Nursing Students: Development and Validation."

Ludwick, D. and J. Doucette (2009). "Primary care physicians' experience with electronic medical records: barriers to implementation in a fee-for-service environment." International Journal of Telemedicine and Applications 2009: 2.

Mannan, R., J. Murphy, et al. (2006). "Is primary care ready to embrace e-health? A qualitative study of staff in a London primary care trust." Journal of Innovation in Health Informatics 14(2): 121-131.

Mills, J., K. Francis, et al. (2015). "Enhancing computer literacy and information retrieval skills: A rural and remote nursing and midwifery workforce study." Collegian 22(3): 283-289.

Neuman, L. W. (2014). Social Research Methods: qualitative and quantitative approaches. England, Pearson.

Rigby, M. J., C. Hulm, et al. (2007). Enabling the safe and effective implementation of health informatics systems-validating and rolling out the ECDL/ICDL Health Supplement. Medinfo 2007: Proceedings of the 12th World Congress on Health (Medical) Informatics; Building Sustainable Health Systems, IOS Press.

Saleh, S., R. Khodor, et al. (2016). "Readiness of healthcare providers for eHealth: the case from primary healthcare centers in Lebanon." BMC health services research 16(1): 644.

Simon, S. R., R. Kaushal, et al. (2007). "Correlates of electronic health record adoption in office practices: a statewide survey." Journal of the American Medical Informatics Association : JAMIA 14(1): 110-117.

Štepankova, O. and D. Engova (2006). "Professional competence and computer literacy in e-age, focus on healthcare." Methods of Information in Medicine 45(03): 300-304.

Terry, A. L., G. Giles, et al. (2009). "Adoption of electronic medical records in family practice: the providers' perspective." Family medicine 41(7): 508.

Van der Meijden, M., H. Tange, et al. (2001). "Development and implementation of an EPR: how to encourage the user." International journal of medical informatics 64(2-3): 173-185.

Ward, R., K. Pollard, et al. (2007). "Developing Information Technology Attitude Scales for Health (ITASH)." Studies in health technology and informatics 129(1): 177. 